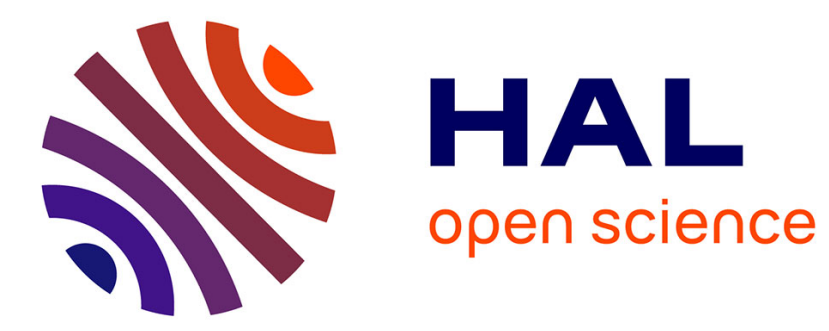

\title{
An Innovation Model for Collaborative Networks of SOA-Based Software Providers
}

João F. Santanna-Filho, Ricardo J. Rabelo, Alexandra A. Pereira-Klen

\section{To cite this version:}

João F. Santanna-Filho, Ricardo J. Rabelo, Alexandra A. Pereira-Klen. An Innovation Model for Collaborative Networks of SOA-Based Software Providers. 15th Working Conference on Virtual Enterprises (PROVE), Oct 2014, Amsterdam, Netherlands. pp.169-181, 10.1007/978-3-662-44745-1_17 . hal-01392108

\section{HAL Id: hal-01392108 \\ https://hal.inria.fr/hal-01392108}

Submitted on 4 Nov 2016

HAL is a multi-disciplinary open access archive for the deposit and dissemination of scientific research documents, whether they are published or not. The documents may come from teaching and research institutions in France or abroad, or from public or private research centers.
L'archive ouverte pluridisciplinaire HAL, est destinée au dépôt et à la diffusion de documents scientifiques de niveau recherche, publiés ou non, émanant des établissements d'enseignement et de recherche français ou étrangers, des laboratoires publics ou privés. 


\title{
An Innovation Model for Collaborative Networks of SOA-based Software Providers
}

\author{
João F. Santanna-Filho, Ricardo J. Rabelo and Alexandra A. Pereira-Klen \\ Department of Automation and Systems Engineering, \\ Federal University of Santa Catarina, Florianopolis, SC, Brazil. \\ joao.santanna@posgrad.ufsc.br, ricardo.rabelo@ufsc.br,xandaklen@gmail.com
}

\begin{abstract}
Software industry has become a very important sector, mostly comprising SMEs. New ICT paradigms have arisen to face new challenges of the economy, namely the Service-oriented architecture (SOA). SOA has the potential to leverage SMEs to new degrees of competitiveness. One of the most relevant drivers for that is innovation. However, SMEs use to be very limited in their resources, and both innovation and SOA are complex, costly and risky. This paper presents preliminary results of an ongoing research towards developing an innovation model that relies on collaboration, enabling software/SOA providers to work as an open network and hence to jointly carry an innovation out. This is important as SOA/software/services sector is very different than manufacturing, to which most of the innovation models are devoted to. The proposed model also identifies the most relevant supporting issues that should be taken into account along the innovation and collaboration processes. The model is presented as well as its rationale. Final considerations about the work are presented at the end.
\end{abstract}

Keywords: Collaborative Networks, Innovation, Software Services, SOA.

\section{Introduction}

Software industry has become nowadays a very important sector. One of its characteristics is that its companies are by far composed of micro, small and medium sized enterprises (SMEs). In Europe, for instance, there are more than fifty thousand SMEs within the ICT sector [1]. SMEs, however, use to have enormous difficulties for engaging general assets to feasibly invest on innovation, infrastructure, growth, training, development and supporting professionals with acceptable risk [2]. Therefore, it is crucial to develop competitiveness models that can allow ICT companies to take advantage of more recent ICT and organizational trends in a sustainable manner.

A number of more recent ICT paradigms have emerged with the potential to leverage that. This paper deals with SOA (Service Oriented Architecture) paradigm. SOA has introduced a new outlook on systems design, development, integration and servitization, provided under a number of architectural, accessing and software business models. In the SOA vision, all system's features are seen as independent and self-contained software modules - called software services - that jointly form virtually a single logical unit to create products and processes. There are some technologies for implementing services-based systems, being web services the most used one [3].

Reports anticipate a SOA market of \$15 billion dollars in 2019, involving an increasing number of emerging enterprises and variable business models [4]. In spite of its potentialities, SOA per se does not guarantee companies sustainability, so other aspects are required. One of them is innovation. Rosenbusch et al. [5] and Li et al. [6] point out that software innovation is a key aspect to increase SMEs competitiveness. 
However, SOA projects are complex, risky, costly and unique, impacting companies (both customers and providers) at many dimensions [3]. SOA deployment also demands several complementary issues that are often provided by partners from larger ecosystems, depending on general business requirements and existing local (at customers and/or providers place) ICT supporting infrastructure and legacy systems.

Therefore, if SOA is intrinsically complex but on the other hand it is a clear trend in terms of business sustainability, how innovation can be leveraged and supported ?

This paper exploits the premise that SMEs of SOA software services providers can mitigate such barriers if they collaborate more intensively with each other. By SOA providers it is meant companies that develop and own (web) services and supporting software services that are able to be composed into more aggregated SOA solutions.

Collaborative Networks $(\mathrm{CN})$ has arisen as a prominent paradigm and supporting foundation to implement strategic alliances grounded on more intense and fluid collaboration among organizations. Its essentials relies on allowing organizations to keep focused on their skills and aggregating competencies and diverse resources with other organizations - so creating networked organizations - in order to offer products with higher value to meet businesses in a better way [7]. This strategic decision can endow them with the possibility of innovating together, developing novel or gathering existing services and solutions from other companies to more effectively and flexibly attend to new/more demands and wider markets. This can provide more valuable and innovative SOA assets for variable customers regarding an increasing need of customizations while ROI and services reuse are maximized [8].

Nevertheless, working collaboratively is not simple. Companies are heterogeneous and autonomous, so their different strategies must be accommodated and interoperate regarding their different priorities and trade-offs in terms of acceptable risks, trust and benefits [7]. Therefore, how can SOA providers innovate collaboratively?

It is important to highlight that a SOA/software product has many differences when compared to manufacturing sector/product, like e.g. development stages and methodologies, supporting constructs, physical deployment, SLA treatment, software quality, and product contracting, access and usage [9]. Yet, development processes also have particularities when a SOA project is carried out collaboratively [10].

A sort of networked-based innovation models have been proposed by many authors. However, none of them are devoted to SOA/software sector and whose services' providers are autonomous SMEs that can participate in all phases of the innovation process, collaboratively and as a network, sharing benefits, costs and risks. Besides that, most of models are very abstract, without providing more detailed processes and even less for a collaborative SOA scenario.

This paper shows preliminary results of an ongoing research which aims to contribute to face this gap, presenting an innovation model that deals with those general requirements. It has been conducted as a research-action, qualitative, deductive and applied work, strongly grounded on literature revision.

The paper is organized as follows. Section has introduced the problem and research goals. Section 2 presents the review of basic foundations. Section 3 presents a review of the state-of-the-art in the tacked problem. Section 4 presents the proposed model. Section 5 provides a summary of the achieved results and next steps. 


\section{Basic Concepts}

This section presents a much resumed description of some of the main core theoretical foundations that have been used in the conception of the proposed innovation model: innovation models; collaborative networks, and governance.

\subsection{Innovation models}

Literature presents several definitions for innovation. This paper adopts the OECD definition, as "the implementation of a new or significantly improved product (good or service), or process, a new marketing method, or a new organizational method in business practices, workplace organization or external relations" [11]. It is of interest of this paper to focus on the product/good type of innovation.

By innovation model it is meant the general conceptual construct that helps an organization and its actors to carry out an innovation (adapted from [12]). The literature presents an extensive set of innovation models. In essence, they basically describe the main phases and general processes necessary to carry an innovation out along and typically via a so-called funnel, namely: selection and/or generation of ideas, concept development, concept evaluation/selection, concept design and specification, implementation and exploitation (adapted from [13]). The intention is that these processes can be instantiated and particularized for any domain and case.

Innovation models have evolved from linear models to network and open models, which can go back and forth through each phase (stage). Evaluation actions (gate) use to be added between each stage so releasing or not the process continuation. Processes can be performed sequentially and/or work in parallel. Different actors can be involved along the innovation process' stages, being intra-organizational members or external partners, and even customers [14].

Regarding this paper's goal, two innovation models are of particular relevance: the Network and Open innovation models [12]. Roughly, the Network model considers an open environment composed of companies prepared and willing to work on an innovative idea when it comes up. Processes and operating rules are set up accordingly. Open innovation focuses on a new logic based in openness and collaboration. It has been often adopted by large corporations that have the innovative idea reasonably well clear and looks for some complementarities and added value in some processes or product's parts. This can come from established partners or from wider ecosystems.

\subsection{Collaborative Networks}

$\mathrm{CN}$ is a general concept that embraces the diverse manifestations of collaboration among organizations. This involves the structure, behavior and evolution dynamics of networks of autonomous entities that collaborate to better achieve common or compatible goals [7]. Two of them are of particular importance in this work: VO (Virtual Organization) and VBE (Virtual organization Breeding Environments). Generally, a VO can be defined as a temporary alliance formed by autonomous and heterogeneous organizations that join their complementary core-competences and resources to attend to a given demand, dismantling itself after all its legal obligations have been accomplished. During its lifecycle (creation, operation, evolution and dissolution) new members can get in and existing members can get out from the VO. 
VOs are mostly originated from long-term alliances, namely a VBE. A VBE in turn formally groups organizations aiming at primarily creating VOs with the most adequate partners in a more agile and trustful way, thanks to enough pre-conditions as well as basic and common operating rules for collaboration which are set up when its members get into it [7]. A VBE is classically seen as a closed world, not supporting at all larger and open digital business ecosystem, i.e. a scenario where other VBEs, other CN, independent actors and even selected customers might be involved in to cope with a joint software business. Adaptations in the VBE concept towards handling that more ample scenario have been proposed, as the Federation concept [8].

Having in mind the envisaged collaborative innovation environment, this paper focuses on how SOA providers SMEs belonging to classical or extended VBEs can form a VO to jointly innovate.

\subsection{Governance}

Governance in Networked Enterprises can be defined as "the definition of rules, criteria for decision-making, responsibilities, and boundaries of actions and autonomy for the involved actors. It is created by the own set of organizations to regulate itself. The fundamental role of governance is not managing, but rather to delimitate the management. Actors can use their knowledge within the defined governance framework in way to help organizations to best reaching their common goals [15].

During the collaboration life cycle companies share assets and sensible information. However, they are independent enterprises and have their own business strategies, creating a complex and intrinsically conflicting operating scenario. Therefore, it is extreme relevant to properly govern that in way to minimize conflicts among all the involved actors and hence the risks for achieving the innovation goals.

Networked enterprises governance have to consider two dimensions: one related to the coordination of the economic activities, and another one to the network structure and the coordination of its activities [15]. The essential rationale of these dimensions is that the market, the given business and power (in a broad sense) influence directly the way a network should execute, monitor and manage its processes and all related information, and hence on how it should be internally organized to correctly and efficiently respond to that.

In the $\mathrm{CN}$ perspective, a $\mathrm{VO}$ embraces different partners, with different roles and so rights and duties, according to the business' profile, VO life cycle and the VBElike/network's principles, bylaws and rules. This should be regulated by the VBE-like and VO governance models [16].

Regarding that the focus of the proposed model is on the innovation processes, the issue of IT or SOA governance [17] is seen as very important but treated at another level, orthogonally along the second funnel's process (see next).

\section{State of the art review}

SLR (Systematic Literature Review) methodology [18] was applied to support this review. It involved the IEEExplore, ACM, and ScienceDirect scientific databases, collecting papers written in English and published in journals and conference proceedings in the period Jan 2000-Feb 2014. This task was complemented with some ad-hoc searches over the Internet. It also comprised a search at CORDIS, the EU 
research projects database. A special attention was put on trying to identify the ones which dealt with SMEs and the software sector.

Any work has been found out after the search which dealt with the envisaged open $\underline{\text { and }}$ networked-based innovation model and devoted to SOA \& software providers. On the other hand, 5 papers and 6 projects presented more useful insights for the proposed innovation model, its processes and constructs.

In terms of papers, in resume, Du Preez et al. [13] have devised an innovation model for products and general services (i.e. not for software services) identifying the most important required macro processes. Berre et al. [19] have proposed supporting languages to express the value delivery and services chain for the general area of services. Hoyer et al. [20] have stressed the obstacles that SMEs face when collaborating towards jointly handling e-business transactions as well as some important constructs and issues to support that collaboration. Belussi et al. [21] have proposed a framework and typology to understand the services (but not software) innovation as a wider and multidimensional evolutionary process, thus helping to better realize the amplitude of the services concept. Li et al. [6] have proposed a model driven collaborative development platform for SOA-based e-business systems. However, they neither focus on supporting innovation nor performing that development within a network.

In terms of EU projects, BIVEE, ComVantage, IMAGINE, CoVES, Laboranova and PLENT [22] have tackled innovation at different perspectives and levels, fundamentally devoted to manufacturing sector, some considering the open innovation model, some don't. Anyone has applied the network innovation model and/or more directed to software or SOA sectors.

\section{Proposed Innovation Model}

\subsection{General Requirements}

In general, the envisaged innovation model intends to endow groups of SOA-related and supporting software SMEs (belonging to a federation-like ecosystem) to carry an innovation out towards providing a (SOA) software (product) solution to attend to a given request. In order to devise the model and processes, this general vision was decomposed into more specific requirements. Such requirements were elicited considering the various foundations and literature review roughly mentioned in the previous sections. The general requirements currently considered are:

1) Companies are autonomous and geographically dispersed SMEs;

2) Companies are SOA software services providers;

3) The 'product' is a SOA-based software, composed of several existing web services, or of web services that need to be developed from scratch or as newer/different versions;

4) A SOA solution can be either a unique software for a given customer or a more general solution that can be further configured to customers;

5) Different companies own services or are in charge of developing such services;

6) This ownership should be protected and duly accounted;

7) Each active web service and its supporting infrastructure/interoperability can be developed / provided by one or by some software companies or ad-hoc supporting partnerships; 
8) Companies can come from different, wider and open digital business ecosystems. They can belong to one or more long-term alliances, or can be completely independent companies;

9) Companies that will participate in the innovation process should be properly selected;

10) Companies may participate along the entire innovation process and software development life cycle, depending on the agreed roles, rights and duties;

11) This participation, the stage in that, and the decision power should be coordinated and regulated according to the given business/innovation needs and general constraints;

12) Companies may/can/should enter to, operate in, and exit from the collaborative innovation network in different moments and number of times, both in the normal operation of the network and when problems, changes or severe conflicts take place;

13) The innovation process and companies' performance should be managed and measured, and web services quality should be certified.

14) The innovation process can be triggered both on customer request and prospectively (by one or more federation's companies). This can have the aim of attending foreseen new businesses, or of coping with initiatives to improve an existing SOA 'product' or part of it;

15) Regarding the intrinsic nature of software services development process, there is not a simple progression, being often necessary going back to earlier stages to overcome difficulties or need for revisions.

\subsection{Basic Rationale}

The model's structure takes the "classical" macro processes proposed by Du Preez et al. [13] into account (section 2.1) since they can comprehensively embrace the general processes considered as necessary for the envisaged model. Processes' names and subprocesses were however adapted to better reflect their core role regarding the intrinsic nature of SOA/software development processes and life cycle (which are different than e.g. the manufacturing sector and its processes, as depicted in [9]).

The ecosystem is not completely open so interested companies need to have some degree of preparedness to be part of it as well as they need to respect some common collaboration/operating rules and ethical principles, as proposed in e.g. [7].

Regarding that SOA and supporting software providers have web services assets and related expertizes, it is important that the interested ones can have the possibility to propose ideas as well as to participate in discussions and initial analyses. Once the idea is approved then selected companies can carry the innovation out. It is important that all necessary expertizes can be joined, covering the diverse dimensions involved in software innovation, such as legal, financial, commercial, technological and software engineering. This should consider not only the innovation development itself but also the after sales phase as SOA products require further assistance and maintenance of several types and intensities.

Regarding the OECD's chain-link model [11], the proposed innovation model is focused on the development of the (SOA) product itself, from the initial ideas exchange to its final delivery. It assumes that market analysis and prospection have been done as well as the decision for being a (total or hybrid) SOA-based product solution has been taken. Yet, that the distribution of the SOA product (in the case of local deployment) and sales/after sales related issues can be up to partners other than the ones involved in the innovation development itself. 


\subsection{The Innovation Model}

The model is showed in Fig 1. It also uses the abstraction of the funnel to represent the multiple ideas going through evaluation phases in a process of funneling and filtering (from left to right) so that only the approved ideas go to be developed.

Inspired in a large cleaning supplies multinational case (although with a different purpose), the classical one-funnel model was split into two funnels. This means that the whole innovation process is performed along two sequential but somehow decoupled macro phases. Whilst the first funnel aims at last to support the discussion and selection of the best ideas and the definition of the respective members of the innovation network (i.e. a VO), the second one aims to indeed develop the selected innovation(s) inside the formed $\mathrm{VO}(\mathrm{s})$. Processes and nature of discussions, type of knowledge, information flow, type of responsibilities, etc., are intrinsically different in each funnel. Regarding that, the innovation behaves more like as network type (see section 2.1) inside the first funnel and more like as open innovation type in the second funnel. In terms of governance model, while the all-ring no-core and buyer-driven models [23] [24] tends to largely prevail in the first funnel, this tends to be more core-ring with coordination firm and information-driven in the second funnel, although much dependent on the current business rules.

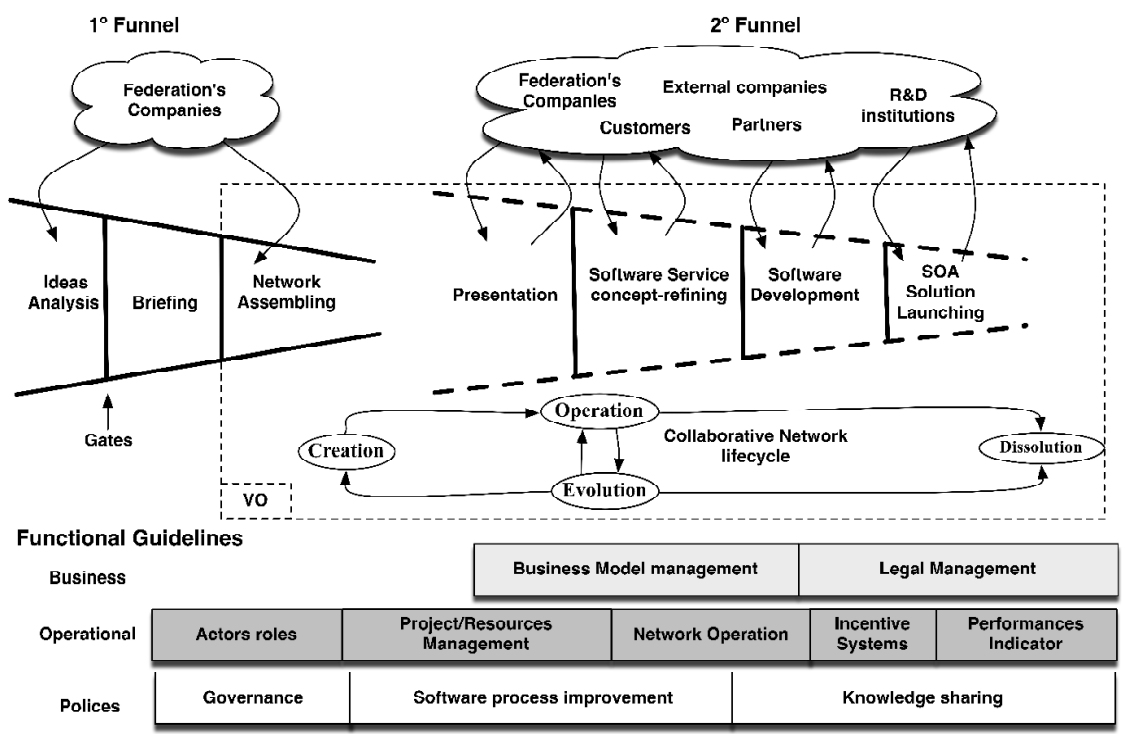

Fig.1. The proposed Innovation Model. Source: authors.

In both funnels the innovation can move forward and backward. However, this tends to happen much more frequently in the first funnel due to the natural not so structured way of exchanging more abstract and business ideas towards more concrete plans. On the other hand, this tends to be more controlled in the second funnel, based on the results evaluation performed in the intermediate gates (illustrated as "vertical lines" separating 
the processes within the funnels) to decide if the whole process can go on or not (in broad terms). Therefore, in general terms, it can be said that a more human-driven approach tends to predominate in the first funnel (using techniques like Design Thinking and Canvas); and a process-driven approach tends to prevail in the second funnel, where the (software) development process is usually better defined and more structured. The entrance and exiting of partners to/from the second funnel is much more fluid than on the first one, whose composition is basically formed by the federation's members. As such, there are different notions of budget, time and human resources allocations, of IPR constraints and legal issues, of governance policies, the role of research, the involvement of existing or the creation of spin-in and spin-offs to exploit intermediate or different facets of the final outcome, and the involvement of customers, experts and external supporting entities in each funnel.

Very briefly, the processes are the following:

First funnel

1) Idea Analysis: one (or group of) company from the federation can propose a joint innovation to the federation's committee (usually comprising multidisciplinary persons), which will firstly evaluate the idea's potential. At this moment the idea is presented shallowly.

2) Briefing: the idea is now detailed presented, describing the necessary technologies, potential partnerships, estimated ROI, foreseen market, etc.

3) Network assembly: formation of the VO that will carry the innovation out. It includes since partners' search and selection till negotiation, VO governance model setting up, revenue mode, specific contract signature, and metrics.

Second funnel

4) Presentation: a complete project plan and ICT technological analysis are conceived and the business model is eventually refined. This is done by the involved companies' managers (the VO innovation committee) helped by some external actor (from inside or outside the federation) depending on the VO governance model. It also includes issues of IPR and ownership, accounting, and knowledge gaps in the VO and in the federation.

5) Software-service conceptualization: it refers to the idealization of the SOA solution, the required services to be composed and their expected QoS and trustworthiness, analysis of existing (observing different versioning and multitenancy aspects) and to-be developed or to-be wrapped services, integration / interoperation / orchestration needs regarding required communication and general and individual execution services infrastructures, UML modeling and Use Cases, mockups, etc. Actually, the essential important goal of this process is to check the envisaged SOA feasibility from the technical perspective.

6) Software development: this process basically deals with the same issues tacked in the previous step, but at a very detailed level. It includes the services coding themselves (with variable software development methodologies), their truly integration and final verifications. It covers the SOA/services life cycle development [9], but with the many particularities when the SOA project is developed by a group of companies [10].

7) Service launching: this last process is the less well defined as it is very dependent on the business, on the contract and its term, target customers and 
associated general legislations, access mode (e.g. local deployment, ASP or SaaS) and definitive running infrastructure. Therefore, this should be all "configured" before finally delivering the SOA product to the 'client' who has requested the innovation.

There is a decision-making step (gate) between each process, so one process only starts if the previous one has been approved after its analysis. This analysis is done adopting agreed and common criteria, a mean to support transparency and trust building among the VO members and other involved actors. Each gate has specific criteria and metrics. Processes can be audited and all relevant knowledge can be stored. All this is defined in the federation and VOs' governance models.

An underlying construct in the proposed innovation model is the VO life cycle (see section 2.2). Its importance is twofold: i) knowing more precisely where the VO is created, operated and dissolved; i.e. being aware of in which processes a VO can change its configuration, including partners entrance/withdrawing and their respective roles; ii) helping partners in the VO management as this requires additional processes for each VO phase other than innovation or software engineering related. These processes have different complexities and demands different efforts, costs and supporting methods from the VO members [7].

\subsection{Functional Guidelines}

Functional guidelines (FG) correspond to supporting aspects that should be considered by network members along the collaborative innovation. It is a construct not presented in other innovation models. They represent methods, techniques, tools and foundations that are required at the different phases of the whole process at different levels. Ten main FGs have been identified as a result of an inductive method over a number of works on innovation from the literature review (e.g. [25] and [26]).

FGs are grouped in three categories, which act at three levels of the innovation process. FGs themselves are positioned within these different levels. Briefly:

- Business level: it embraces the FGs related to the innovation commercialization, in more particular: business model management (elements to guarantee that the innovation results are aligned with the defined business model), and legal management (to guarantee that the innovation results have been developed and are aligned within the required legal framework, respecting contracts, IPR and services ownership).

- Operational level: it embraces the FGs to support the "daily" operation of the innovation development, in more particular: the actors management (to guarantee that all the involved actors will consider their rights and duties according to the governance model); Project/Resources management (it supports the usual issues related to manage the innovation process as a project, including associated human, financial and material resources); Network operation (it is also related to the governance model, adapting the power and structural elements of decisionmaking as long as the innovation process goes on); Incentive systems (issues to guarantee the correct application of incentives to collaborate in the innovation also regarding productivity and adherence to the project's goals); and Performance indicators (selection and application of adequate indicators to correctly measure 
and manage the performance of the project, individual services, partners and the innovation itself).

- Policies level: it embraces the FGs related to general relations among the VO, the VO with other actors (internal or external to the federation), and with customers. In more particular: Governance (rules and models to set up how the innovation will be done and managed); Software process improvement (models, standards, specifications, practices, IT and SOA governance, and methodologies to guarantee the right way of developing software and services); and Knowledge sharing (to guarantee that the necessary information and knowledge - of all types - to support the innovation are properly shared, that lessons can be learned, etc.).

These FGs and their placement along the innovation process should however be seen here as a reference. Therefore, regarding the particularities of the given ecosystem in terms of e.g. existing culture, type of customers, adopted business models, and regional/national/international accounting and legal frameworks and associated requirements, they can support processes in a different way and can have different degrees of importance. New FGs can also be added for given instantiations.

\section{Final Considerations}

This paper has presented preliminary results of a research which aims at conceiving an innovation model devoted to support collaborative innovation among SMEs of SOA software services providers towards a SOA solution.

The proposed model has been developed in the light of Collaborative Networks, enabling SMEs to work as a network, so sharing costs, risks and benefits. A Virtual Organization (VO) represents the group of SMEs that jointly carry the innovation out. One of the underlying assumptions is that they should come from an ecosystem of ICT companies, which should have some preparedness to collaborate and that share common principles and operating rules.

However, quite few works have dealt with collaborative innovation targeting networked SMEs and anyone looking at the software services sector and related products. Besides that, most of the innovation models that have been proposed are directed to manufacturing, a sector very different than the SOA/software sector.

Collaborative innovation has the potential to leverage SMEs of software and, in more particular, of SOA providers, to new degrees of sustainability. This ascends in significance as SOA represents one of the most powerful ICT drivers and future directions but at the same time brings lots of complexity to software projects. The proposed model represents a contribution to mitigate this problem, helping networked companies in conducting a joint innovation. This is supported not only via a more intense software services assets reuse, but also permeating the network with a fluid participation of external actors.

The proposed model also identifies the most relevant supporting issues that should be taken into account along the innovation process and the VO life cycle. To be highlighted the governance issue, fundamental to guarantee the correct evolution of a given innovation as long as it progresses, regulating partners' roles, rights and duties. This mitigates conflicts among companies and hence the innovation risks. Such issues, taken as functional guidelines in the proposed model, helps companies to allocate 
proper resources and be aware about different levels of complexities along the collaborative innovation SOA life cycle.

Regarding the particularities of software/SOA sector, the nature of the innovation process, and the fact that companies should work in a network, the classical innovation funnel was adapted and split into two sequential but decoupled funnels. The first funnel works more under the network innovation model and the second under the open innovation model. The innovation flow can move forward and backward in both funnels and, per definition, partners can be involved in many steps and with variable intensities along the innovation process.

This innovation model is focused on SMEs of SOA providers, and not to traditional software developed internally (although eventually in a distributed way) by one company. Yet, it is not devoted to Internet-oriented companies niche that develop small apps-like software applications typically on their own.

Collaborative innovation and even less collaborative software innovation and SOA are recent topics and most of SMEs are still giving the first steps towards that. As such, the adoption of this model by SMEs of SOA-based companies tends to also follow a natural maturity process, an obstacle largely pointed out in the literature on collaborative networks but for which a number of supporting methodologies have been proposed and implemented.

Next steps of this research include the verification of the model and its elements close to a real cluster of ICT/SOA providers already identified for further refinements. The final evaluation of the model is expected to be performed via a working group and structured questionnaires (Expert Panel technique) to be applied close to a cluster of real of ICT/SOA companies placed in the South of Brazil. Refinements on top of the work of [10] in terms of detailed processes and practices to develop SOA collaboratively is a task also planned to be done, besides the conception of an implementation guideline of the model.

\section{Acknowledgements}

This work has been supported by the CNPq Brazilian research funding agency.

\section{References}

1. http://www.ukita.co.uk/about-ukita/about-ukita.html

2. Westphal, I., Thoben, K. D., Seifert M.: Managing collaboration performance to govern virtual organizations. Journal of Intelligent Manufacturing, Vol 21/3, pp.311-320 (2010)

3. Papazoglou, M.P.: Web Services \& SOA, Principles and Technology. Pearson (2012)

4. PRWEB,http://www.prweb.com/releases/soa-services-oriented/architecture-market/ prweb10670370.htm

5. Rosenbusch, N., Brinckmann, J., Bausch, A.: Is innovation always beneficial? A metaanalysis of the relationship between innovation and performance in SMEs. Journal of Business Venturing 26, 441-457 (2011)

6. Li, Y., Shen, J., Shi, J., Shen, W., Huang, Y., Xu, Y.: Multi-model driven collaborative development platform for service-oriented e-Business systems. Advanced Engineering Informatics 22, 328-339 (2008)

7. Camarinha-Matos, L., Afsarmanesh, H.: Collaborative Networks: Reference Modeling. Springer Publishing Company, Incorporated (2008) 
8. Rabelo, R.J.: Advanced collaborative business ICT infrastructures. Methods and Tools for collaborative networked organizations, pp. 337-370. Springer (2008)

9. O'Brien, L.: A framework for scope, cost and effort estimation for service oriented architecture (SOA) projects. In: IEEE Software Engineering Conference, 2009. ASWEC'09. , pp. 101-110. IEEE.

10. Cancian, M. H., Rabelo, R. J., Wangenheim C. G.: Supporting Processes for Collaborative SaaS, Proc. 14th Working Conference on Virtual Enterprises, Springer, pp. 183-190 (2013)

11. OECD: Guidelines for collecting and interpreting technological innovation data. (1997)

12. Tidd, J., Bessant, J., Pavitt, K.: Innovation Management. Willey (2001)

13. Du Preez, N. D., Louw L.: A framework for managing the innovation process. Proc. Portland Int. Conf. on Management of Engineering \& Technology, pp. 546-558 (2008)

14. Rothwell, R.: Successful industrial innovation: critical factors for the 1990s. R\&D Management 22, 221-240 (1992)

15. Roth, A.L., Wegner, D., Padula, A. D.: Differences and Inter-Relations of Governance Concepts and Horizontal Networked Enterprises Managemen. Journal of Administration [in Portuguese], vol. 1, pp. 112-123, Brazil (2012)

16. Costa, S.N., Rabelo, R.J.: "A Governance Model for Virtual Enterprises" [in Portuguese]. in Proc. XVI Symposium on Manufacturing Management, Logistics and International Operations, pp. 1-12, São Paulo, Brasil

17. Brown, W. A., Laird, R. G., Gee, C., Mitra, T.: SOA Governance: achieving and sustaining business and IT agility, IBM Press, 2009.

18. Kitchenham, B., Pearl Brereton, O., Budgen, D., Turner, M., Bailey, J., Linkman, S.: Systematic literature reviews in software engineering - A systematic literature review. Information and software technology 51, 7-15 (2009)

19. A. J. Berre, Y. Lew, B. Elvesaeter, and H. de Man, "Service Innovation and Service Realisation with VDML and ServiceML", in 7th IEEE International Enterprise Distributed Object Computing Conference Workshops (EDOCW), pp. 104-113 (2013)

20. Hoyer, V., Christ, O.: Collaborative e-business process modelling: a holistic analysis framework focused on small and medium-sized enterprises. Proceedings 10th international conference on Business information systems, pp. 41-53. Springer, Poznan, Poland (2007)

21. Belussi, F., Arcangeli, F.: A typology of networks: flexible and evolutionary firms. Research Policy 27, 415-428 (1998)

22. http://cordis.europa.eu/projects/home_en.html

23. Storper, M., Harrison, B.: Flexibility, hierarchy and regional development: The changing structure of industrial production systems and their forms of governance in the 1990s. Research Policy 20, 407-422 (1991)

24. Gereffi, G., Humphrey, J., Sturgeon, T.: The governance of global value chains. Review of international political economy 12, 78-104 (2005)

25. Munkongsujarit, S., Srivannaboon S.: Key success factors for open innovation intermediaries for SMEs: A case study of iTAP in Thailand, in Proceedings of PICMET '11 Technology Management in the Energy Smart World, pp. 1-8 (2011)

26. Van Zyl, J.: Process innovation imperative [software product development organisation]. Proceedings IEMC'01 - Change Management and the New Industrial Revolution, pp. 454$459(2001)$ 